results for the Backcross group correlated +.72 , significant at the .01 level. This was interpreted as evidence for genetic segregation of the trait in the Backcross group.

A similar procedure was carried out for the C57BL/6J inbred males and the three segregating groups of the current experiment. The sample size in the replication was smaller than that shown in Table 1. Forty C57BL/6J males were retested, as were from 100 to 120 males in each of the three segregating populations. Once again, an insignificant correlation (t.12) was found for the C57BL/6J group. Correlations for the segregating populations ranged from +.20 to +.40 and were significant in all three cases. This finding supports our previous conclusion regarding genetic segregation in terms of the time required to recover sex drive in this particular test situation.

Unfortunately, the score distributions resulting from the tests of the present experiment do not meet the necessary criteria for further biometrical analyses (Bruell, 1962). This is true whether raw scores, or logarithms, or square roots of the raw scores are used. However, following an example given by Bruell (1962) who had similarly skewed distributions, Fig. 1 depicts the pattern of inheritance when median scores are plotted. As Fig. 1 shows, the median scores for the segregating populations (solid circles) fall very close to the points that are predicted (open circles) on the basis of the nonsegregating populations. (Formuli used in redicting the medians of the segregating populations shown in Fig. 1 are given in Bruell, 1962.)

While Fig. 1 clearly indicates dominance of the DBA/2J genotype in the determination of recovery of sex drive, it should be noted that the design of the experiment did not permit any overdominance present to reveal itself, since the first recovery test was not given until $1 \mathrm{~h}$ after the initial ejaculation. However, the distributions of scores for the DBA/2J and F1 groups in Table 1 would indicate that overdominance is probably not present for this particular cross for this trait, i.e., the mean recovery time for F1 is actually a bit higher than that for $\mathrm{DBA} / 2 \mathrm{~J}$.

The results of this experiment indicate a definite genetic effect on recovery of sex drive in the male mouse (Fig. 1). However, the results and conclusions are specific to the total experimental environment described above. It is doubtful that our test situation measures the minimum absolute refractory period following ejaculation. Consider the large range found for the C57BL/6J males as shown in Table 1. It seems unreasonable to suppose that these males vary so greatly in physiological recovery time. Furthermore, when the experiment was repeated for 40 of these

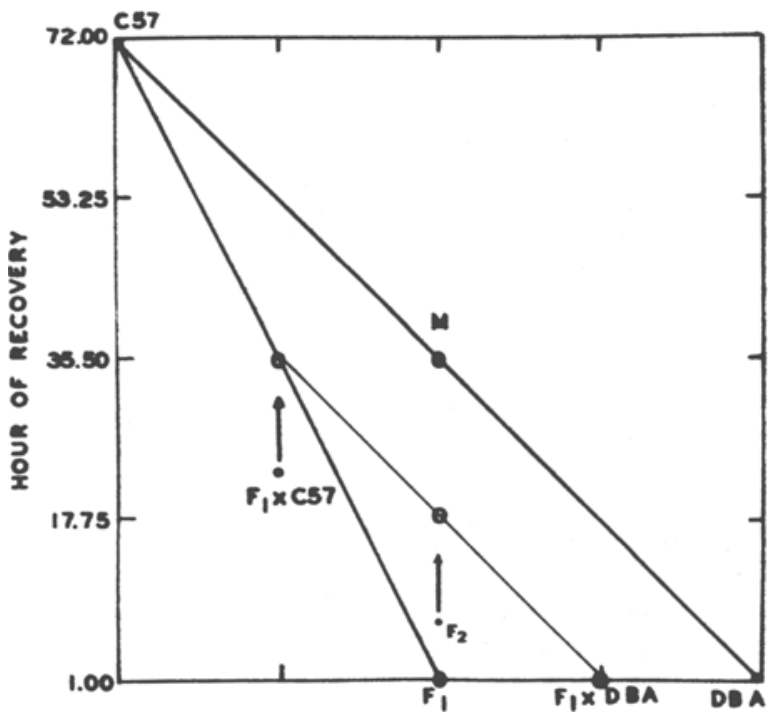

Fig. 1. Observed (solid circles) and expected (open circles) medions (see Bruell, 1962). $M=$ midparent.

males, the range and median were replicated almost exactly, but the test-retest correlation was not significant. Therefore, not only is there a large range of response in a group of these inbred males, but a single male, retested many times, would probably show similar variability. In discussing the results for this strain, McGill and Blight concluded, "Apparently the recovery of a C57BL/6J male is greatly influenced by transient, and unknown, environmental factors." This conclusion is supported by the lack of a significant correlation between the test-retest results of the present study. Ginsburg (1965) has listed a variety of behavioral and morphological measures for which the C57BL strain showed great variability. He concluded that this particular genotype is highly susceptible to environmental changes. This susceptibility can result in permanent changes such as increased skeletal variability, or in transient differences such as were observed in the present experiment.

\section{REFERENCES}

BRUELL, J. H. Dominance and segregation in the inheritance of quantitative behavior in mice. In E. L. Bliss (Ed.), Roots of behavior. New York, N.Y.: Harper \& Brothers, 1962.Pp. 48-67.

GINSBERG, B. E. Questions and group discussion. In F. A. Beach (Ed.), Sex and behwior. New York, N.Y.: John Wiley \& Sons, 1965.P. 87

McGILL, T. E., \& BLIGHT, W. C. Effects of genotype on the recovery of sex drive in the male mouse. Joumal of Comparative \& Physiological Psychology, 1963, 56, 887-888. NOTES

1. This research was supported by Research Grant 07495 from the Institute of General Medical Sciences, U.S. Public Health Service.

2. The hormone preparations were generousiy supplied by Dr. Preston L. Perlman, Schering Corporation, Bloomfield, New Jersey.

\title{
Absence of change in some measures of cortical morphology in dark-reared adult rats'
}

JUDITH A. R. BOAS, R. L. RAMSEY, A.H.
RIESEN, and J. P. WALKER, University of
California, Riverside, Calif. 92502

The frontal and visual cortices of 200-day-old rats were microscopically examined after staining with Golgi-Cox.
Measures included cellular density, total thickness of cortex, thickness of Layers 1 and 3 , and nuclear volumes in three layers. No differences between dark- and lightreared $S s$ were found within brain regions. The data are interpreted in terms of current literature on cortical effects of sensory deprivation. 
Cortical changes following prolonged sensory deprivation are proving to be subtle and relatively temporary by comparison with subcortical effects. Krech et al (1963) reported a greater decrease in subcortical optical areas than in striate cortex in 80-day-old blinded rats. Gyllensten et al (1965) reported the eventual normalization of hypotrophy in cortical but not subcortical areas of mice that had been dark-reared and never exposed to light; and Maletta \& Timiras (1968) found a decrease in choline acetyltransferase activity and total protein content in subcortical but not cortical areas after dark-rearing.

Morphological changes may be more marked in young animals which have been exposed to deprivation (Fox et al, 1968). Globus \& Scheibel (1967) report great decreases in the number of apical dendritic spines in Layer 4 of the striate area after neonatal enucleation or lesions of the lateral geniculate body. Valverde (1967) also reported a decrease in the number of dendritic spines after dark-rearing, and in another study discovered that, in enucleates, the loss of spines is greater in younger Ss (Valverde, 1968). Coleman \& Riesen (1968) reported decreased dendritic proliferation of Layer 4 stellate cells in 6-morth-old dark-reared cats. The functional status of visual cortex in blind human beings is a question of crucial importance in the development of prosthetic systems (Brindley \& Lewin, 1968).

The purpose of the present study was to investigate the cortical morphology of dark-reared rats at maturity. The period of deprivation was 3 months longer than that employed by Gyllensten (with mice).

\section{METHOD}

Three Ss were placed in a dark room on the day of birth and sacrificed at Day 200 in the dark. Three control Ss were reared in the lighted laboratory. The brains were frozen, sliced, and prepared with a Golgi-Cox stain. Every 10th section was mounted. There were approximately 15 slides for the frontal area and 15 slides for the striate area of each animal. The slides were viewed magnified 400X under oil immersion using an $\mathrm{AO}$ microscope with a screen. Measurements were taken by two Es under blind design conditions. Cellular density was calculated by counting the number of cells in equal horizontal areas of tissue. Measurements were taken at 10 different cortical depths.

Layer thickness and total thickness of cortex was obtained by projecting the image on a piece of paper under lower magnification, drawing the outline, and measuring the thickness in millimeters. Layer thickness was obtained for Layers 1 and 3.

Nuclear volume was obtained by selecting the three largest cells from each sample of Layers 1, 2, and 3, and measuring length and
Table 1

Cortical Layer Thickness (Averages in $\mathrm{mm}$ under magnification of $\mathbf{4 0 0}$ times)

\begin{tabular}{lcccc}
\hline & \multicolumn{2}{c}{ Dark-reared } & \multicolumn{2}{c}{ Light-reared } \\
& Frontal & Visual & Frontal & Visual \\
\hline Layer 1 & .112 & .130 & .117 & .112 \\
Layer 3 & .302 & .228 & .287 & .229 \\
$\begin{array}{l}\text { Total Thick- } \\
\text { ness of } \\
\text { Cortex }\end{array}$ & 1.171 & .936 & 1.178 & .949 \\
\hline
\end{tabular}

width in millimicrons. Volume was calculated according to the formula, $V=(1 / 6) \pi 1 w^{2}$

\section{RESULTS AND DISCUSSION}

There were no meaningful differences between the two groups on any of the five measures, and the differences between groups were no greater than the between-S variation. The data for the two groups were so similar that a statistical analysis was deemed unnecessary. Table 1 presents the mean values for thickness of layers.

These data confirm and extend the report of Gyllensten et al (1965) who found (in mice) a relative decrease in the volume of internuclear material and cortical thickness at 1 and 2 months and subsequent partial normalization at 4 months. We find complete normalization in rats at 7 months. Similar normalization in subcortical visual centers has not been reported.

Two hypotheses have been offered to explain the smaller changes observed at the cortical level after deprivation. The first holds that spontaneous firing, lower in the system, may provide enough tonic bombard ment to prevent gross changes. Many retinal ganglion cells continue to discharge in total darkness for long periods as has been shown by Burke \& Hayhow (1968), who found that the LGN response of adult cats kept in complete darkness for periods of up to 966 days was not appreciably different from that in the normal cat. Whether this discharge continues in dark-reared Ss is still unknown.

This hypothesis is also supported by Globus \& Scheibel (1967), who reported twice as great a loss of dendritic spines with enucleation as with incomplete lesions of the lateral geniculate, and by Gyllensten et al (1967), who reported that enucleation produces a greater degree of hypotrophy than does dark-rearing and does not permit subsequent normalization. The hypothesis may explain the lack of normalization at lower levels. Because of its complex network structure, a single afferent impulse will cause more cortical cells to fire than vertical LGN cells which maintain more of a one-to-one relation with the retinal discharge. The disadvantage of the hypothesis is that it fails to account for the puzzling biochemical results-an increase of cholinesterase in visual and somesthetic areas after enucleation (Krech et al, 1963).
Another frequently stated hypothesis is that in blind animals the visual areas may come to subserve nonvisual functions. Krech et al (1963) showed that stimulation from an enriched environment is "equally beneficial to enucleated rats." In short, with complete elimination of visual input, the visual cortex continues to be affected by variations in the animal's experience.

The two hypotheses should not be considered as mutually exclusive, and our data cannot differentiate between the two. Until the role of spontaneous firing in visual centers is clearly delineated, the question must remain open. Meanwhile, studies of morphologic correlates of prolonged sensory deprivation are likely to reveal changes in carefully localized finer structures of dendrites (Valverde, 1967, 1968) and synapses even when cell diameters and cortical layer thickness show normalization.

\section{REFERENCES}

COLEMAN, P. D., \& RIESEN, A.H. Environmental effects on cortical dendritic fields. I. Rearing in the dark. Journal of Anatomy, 1968, 102, 363-374.

BRINDLEY, G. S., \& LEWIN, W.S. The sensations produced by electrical stimulation of the visual cortex. Journal of Physiology, 1968, 196, 479-493.

BURKE, W., \& HAYHOW, W. R. Disuse in the lateral geniculate nucleus of the cat. Joumal of Physiology, 1968, 194, 495-519.

FOX, M. W., INMAN, O., \& GLISSON, S. Age differences in central nervous effects of visual deprivation in the dog. Developmental Psychobiology, 1968, 1, 48-54.

GLOBUS, A., \& SCHEIBEL, A. B. Synaptic loci on visual cortical neurons of the rabbit: The specific afferent radiation. Experimental Neurology, 1967, 18, 116-131.

GYLLENSTEN, L., MALMFORS, T., \& NORRLIN, M.L. Effect of visual deprivation on the optic centers of growing and adult mice. Journal of Comparative Neurology, 1965, 124, 149-160.

GYLLENSTEN, L., MALMFORS, T., \& NORRLIN-GRETTVE, M. L. Visual and non-visual factors in the centripetal stimulation of postnatal growth in the visual centers in mice. Journal of Comparative Neurology, 1967, 131 , 549-558.

KRECH, D., ROSENZWEIG, M. R., \& BENNETT, E. L. Effects of complex environment and blindness on rat brain. Archives of Neurology, $1963,8,403-412$.

MALETTA, G. J., \& TIMIRAS, P. S. Choline acetyltransferase activity and total protein content in selected optic areas of the rat after comple te light-deprivation during CNS development. Journal of Neurochemistry, 1968, 8 , 787-794.

VALVERDE, F. Apical dendritic spines of the visual cortex and light deprivation in the mouse. Experimental Brain Research, 1967, 3 , 337-352.

VALVERDE, F. Structural changes in the area striata of the mouse after enucleation. Experimental Brain Research, 1968, 5, 274-292.

NOTE

1. Supported by PHS Grant NB-14707. The technical assistance of Miss Rebecca Vick is gratefully acknowledged. 